\title{
Coxiella burnetii e a febre Q no Brasil, uma questão de saúde pública
}

\author{
Coxiella burnetii and Q fever in Brazil: a public health issue
}

Iangla Araujo de Melo Damasceno ${ }^{1}$

Ricardo Consigliero Guerra ${ }^{1}$

${ }^{1}$ Faculdade de Ciências Humanas, Econômicas e da Saúde de Araguaína, Instituto Tocantinense Presidente Antônio Carlos. Av. Filadélfia 568, Setor Oeste. 77816-540 Araguaína TO Brasil. iangla@hotmail.com

\begin{abstract}
Q$ fever is a zoonosis that is broadly distributed worldwide, despite few reports associated with its occurrence in Brazil. Coxiella burnetii, namely the causative agent of $Q$ fever is a gram-negative coccobacillus and an obligate intracellular bacterial parasite of the order of Legionellales. The microorganism is generally present in the urine and feces of infected animals and can be found in large quantities in placental membranes of at-term or aborted animals. The inhalation of particles suspended in the air or contaminated aerosols is the most common form of bacterial contact. Q Fever is a self-limited disease, and often progresses in a benign way. In cases where the disease progresses to the chronic form, endocarditis is the most prevalent manifestation. Clinical diagnosis is difficult since the symptoms are similar to many other diseases. In confirmed cases, antibiotic therapy is the treatment indicated. Given the lack of knowledge about the disease and the difficulty of diagnosis, it is believed that $Q$ fever is more common than generally believed in Brazil.
\end{abstract}

Key words Coxiella burnetii, Occupational exposure, Zoonosis
Resumo A Febre Q é uma zoonose de ampla distribuição mundial, apesar dos poucos relatos associados a sua ocorrência no Brasil. "Coxiella burnetii", agente etiológico da Febre Q, é um cocobacilo gram-negativo, parasita intracelular obrigatório da ordem Legionellales. O microrganismo geralmente está presente na urina e fezes de animais infectados, podendo ser encontrado em grande quantidade nos restos placentários de animais nascidos a termo ou produtos de aborto. A inalação de células bacterianas suspensas no ar ou aerossóis contaminados é a forma mais comum de entrar em contato com a bactéria. A febre $Q$ é uma doença autolimitada e, geralmente, evolui de forma benigna. Nos casos onde a doença evolui de forma crônica, a endocardite é a manifestação mais frequente. O diagnóstico clínico é difícil, visto que os sintomas assemelham-se a várias outras doenças. Nos casos confirmados a antibioticoterapia é o tratamento indicado. Diante da sintomatologia pouco específica e dificuldade de diagnóstico, acredita-se que no Brasil a doença seja mais comum do que se pensa.

Palavras-chave Coxiella, Exposição ocupacional, Zoonose 


\section{Introdução}

A bactéria Coxiella burnetii é o agente etiológico da doença conhecida como Febre Q, uma zoonose de distribuição mundial. Geralmente a infecção apresenta quadros leves, com simples manifestações febris, apenas em alguns casos evolui com manifestações clínicas graves ${ }^{1,2}$.

Há poucos relatos da doença no Brasil, onde a notificação dos casos em animais ou humanos não é compulsória. Em razão da sintomatologia não ser específica, o diagnóstico clínico é dificultado, não havendo um protocolo que defina orientações aos profissionais médicos e veterinários sobre as manifestações clínicas da infecção, tratamento e condutas a serem adotadas ${ }^{2}$.

Na Europa e Oceania, especialmente na Austrália onde foi descrita pela primeira vez, a doença é bastante comum e de notificação compulsória. Apesar disso alguns autores a consideram subnotificada, tanto em animais como em humanos, em decorrência das dificuldades encontradas em se realizar o diagnóstico ${ }^{2-5}$.

Nesse contexto esta revisão tem o objetivo de esclarecer alguns aspectos relacionados à zoonose, principais sintomas, métodos de diagnóstico e tratamento, assim como possíveis complicações associadas à evolução da doença. Este conjunto de informações tem a finalidade de orientar profissionais da saúde, estudantes, médicos veterinários e a população em geral, especialmente o trabalhador rural que lida diretamente com a produção animal e seus subprodutos, fonte primária da infecção.

\section{Materiais e métodos}

Foi realizada uma revisão sistemática da literatura com o objetivo de levantar dados sobre a ocorrência da febre $\mathrm{Q}$ no Brasil, bem como identificar as características básicas do agente causador e da doença. Sendo assim, a revisão foi elaborada por meio do levantamento de publicações disponíveis nas bases de dados Scielo, Pubmed e Science Direct, utilizando os descritores: Q fever; Coxiela burnetii; Endocarditis.

\section{Histórico}

A febre $\mathrm{Q}$ foi descrita inicialmente na Austrália em 1935, quando Edward Holbrook Derrick foi convidado a investigar uma doença em um grupo de trabalhadores de um matadouro. Por desconhecê-la, passou a denominá-la Query
Fever. Já em 1937, os pesquisadores Frank Macfarlane Burnet e Mavis Freeman classificaram o microrganismo causador da doença como pertencente ao gênero Rickettsia, passando a denominá-lo Rickettsia burnetii $i^{2,3,6}$.

Enquanto isso em Montana, nos Estados Unidos, um grupo de pesquisadores liderados por Herald R. Cox, também desenvolvia trabalhos com um microrganismo desconhecido (inicialmente chamado agente Nine Mile). Somente mais tarde foi possível perceber que se tratava do mesmo microrganismo estudado por Burnet $\mathrm{e}$ Freeman. Em 1948, após identificação molecular, a bactéria foi descrita como pertencente ao gênero Coxiella. Assim, em homenagem aos dois grupos de pesquisadores recebeu o nome de $\mathrm{Co}$ xiella burnetii $i^{2,3,6}$.

Após esse período de reconhecimento e classificação do agente etiológico vários países vêm notificando casos em animais e humanos, dentre eles a Holanda. Este país registrou 4.000 casos em humanos no período de 2007 a 2010, somente em 2009 foram 2.361 casos com 6 mortes, até então a maior epidemia registrada na Europa. No ano de 2008, os EUA confirmaram 132 casos (117 casos de doença aguda e 15 crônicos). No entanto, em ambos os países a notificação é compulsória ${ }^{7-10}$.

No ano de 2006, durante a reunião anual da American Veterinary Association, em Honolulu, Hawaii, um estudo investigou 508 veterinários que participavam da reunião. Os participantes selecionados atendiam a critérios de risco ocupacional associado ao contato com a bactéria, tais como: idade superior a 46 anos, contato com gado bovino, suínos ou animais selvagens. Os resultados dos testes indicaram sorologia positiva para C. burnetii em 133 (26,2\%) dos profissionais ${ }^{5}$.

O Brasil apresentou o primeiro relato em $1953^{11}$. Desde então, as publicações sobre a doença são escassas. Um dos primeiros estudos sobre a febre Q no Brasil foi elaborado por Ribeiro-Netto et al. ${ }^{12}$, os autores analisaram o soro de 200 ordenhadores e tratadores de rebanhos bovinos do Vale do Paraíba, no Estado de São Paulo, desse total 17 amostras foram positivas.

Lemos et al. ${ }^{1}$ desenvolveram um estudo que identificou a primeira prova molecular da bactéria no Brasil. Os pesquisadores utilizaram a técnica de Reação em Cadeia de Polimerase (PCR) para confirmar a infecção em um homem de 47 anos, com relato de contato prévio com cabras e produto de aborto de animais.

No Quadro 1 é apresentado um breve histórico das pesquisas publicadas sobre a circulação da 
Quadro 1. Trabalhos publicados sobre casos confirmados ou diagnosticados no Brasil

\begin{tabular}{|c|c|c|c|}
\hline Autores & Data & Localidade & Método diagnóstico / espécie pesquisada \\
\hline Brandão et $\mathrm{al}^{11}$ & 1953 & São Paulo & Sorologia/humano \\
\hline Ribeiro-Netto et al. ${ }^{12}$ & 1964 & São Paulo & Sorologia/humano \\
\hline Riemann et al. ${ }^{13}$ & 1974 & Belo Horizonte & Sorologia/humano \\
\hline Riemann et al. ${ }^{14}$ & 1975 & Belo Horizonte & Sorologia/humano \\
\hline Costa et al. ${ }^{15}$ & 2005 & ----------- & Sorologia/humano \\
\hline Costa et al. ${ }^{6}$ & 2006 & Juiz de Fora- MG & Sorologia/humano \\
\hline Siciliano et al. ${ }^{16}$ & 2008 & São Felipe- BA & Sorologia e anatomopatológico/ humano \\
\hline Lamas et al. ${ }^{17}$ & 2009 & Jacarepaguá- RJ & Sorologia \\
\hline Lemos et al. ${ }^{1}$ & 2011 & Itaboraí- RJ & Sorologia e Molecular (PCR)/ humano \\
\hline Rozental et al. ${ }^{18}$ & 2012 & Rio de Janeiro & Molecular/ Humano \\
\hline Lamas et al. ${ }^{19}$ & 2013 & Rio de Janeiro & Molecular/ Humano \\
\hline Mares-Guia et al..$^{20}$ & 2014 & Itaboraí- RJ & $\begin{array}{l}\text { Sorologia e Molecular (PCR)/ } 14 \text { cães, } 1 \text { gato, } 10 \\
\text { cabras, } 3 \text { ovelhas e } 2 \text { cavalos. }\end{array}$ \\
\hline
\end{tabular}

Fonte: Levantamento de dados da pesquisa.

doença no país. É importante que os dados sejam vistos como um alerta às autoridades sanitárias sobre a ocorrência da doença no Brasil.

Analisando a tabela podemos observar que os primeiros dados sobre a febre $Q$ no país são da década de 50, depois há um lapso de tempo, em torno de 10 anos, entre as publicações na década de 70. Após um longo período, em torno de três décadas, a partir do ano de 2005, as notificações tornam-se mais frequentes, porém, vale ressaltar que a confirmação da doença no país, por métodos moleculares, só foi possível no ano de 2011. Grande parte desses trabalhos foi concebido por meio dos esforços de um grupo de pesquisadores do Laboratório de Hantaviroses e Ricketisoses da Fundação Osvaldo Cruz (Fiocruz).

\section{Agente etiológico}

Pelo fato do metabolismo ser exclusivamente intracelular, Coxiella burnetii foi anteriormente classificada no gênero Rickettsia. Hoje se sabe, baseado em investigações filogenéticas do RNAr $16 \mathrm{~S}$, que essa bactéria pertence à ordem das Legionellales, grupo gama das Proteobactérias. Trata-se de um cocobacilo gram-negativo, intracelular obrigatório e de alta resistência ${ }^{18,21}$.

O microrganismo apresenta alta resistência ao calor, podendo suportar até 30 minutos sob temperatura de $60^{\circ} \mathrm{C}$. Em função dessa característica, o método de pasteurização tradicional do leite sofreu alterações por não atender aos pa- drões de segurança alimentar. Durante a pasteurização rápida a temperatura do leite cru é mantida à $72^{\circ} \mathrm{C}$, por um período de 15 segundos. Este método é considerado mais eficaz na destruição do microrganismo e aceito pelas autoridades sanitárias ${ }^{22}$.

Após a invasão do organismo do hospedeiro, por meio das vias aéreas, os alvos preferenciais da infecção são os macrófagos alveolares e as células de Kupffer presentes no fígado. Por meio da fagocitose a bactéria é endocitada pelos macrófagos, formando um vacúolo parasitóforo (VP). No interior dessa estrutura, o microrganismo consegue retardar o processo de defesa do organismo, impedindo a ligação inicial dos lisossomos ao VP por aproximadamente 2 horas. Após esse período ocorre fusão das vesículas lisossômicas à membrana do VP, tornando o ambiente acidificado pelos lisossomos, condição propícia à multiplicação da bactéria, que resiste à acidez e ação das enzimas no VP e se reproduz por divisão binária ${ }^{2,23,24}$.

Diferentemente de outros microrganismos intracelulares, uma importante característica fisiológica da C. burnetii está no fato da alteração do $\mathrm{pH}$ do meio não ser necessária para início de sua replicação. No entanto, o pH ácido favorece o processo de assimilação de nutrientes essenciais ao seu metabolismo, o que constitui considerável obstáculo ao tratamento da infecção. A maioria dos fármacos utilizados tem sua eficácia diminuída no ambiente ácido dos vacúolos fagolisossô- 
micos, produzindo apenas uma ação bacteriostática $^{2,23,25}$.

No hospedeiro, a bactéria pode infectar vários tipos celulares: macrófagos, monócitos, fibroblastos e células epiteliais. Após a infecção, o desenvolvimento da bactéria pode ocorrer de duas formas: uma metabolicamente inativa e outra ativa.

A metabolicamente inativa é denominada Small-Cell Variant (SCV). É compacta, altamente resistente e permanece viável por mais tempo no ambiente extracelular. A metabolicamente ativa é denominada Large-Cell Variant (LCV), é intracelular, maior e menos densa. Por meio de um processo de diferenciação esporogênica (semelhante à esporulação), a forma LCV pode converter-se na forma inativa SCV. A ruptura da célula hospedeira infectada libera a forma SCV, que pode ser dispersa no ambiente por meio de urina, fezes, leite e restos placentários ${ }^{2,3,6,9,10,16,18,25}$.

Coxiella burnetii apresenta, ainda, uma variação de fase no decorrer da infecção, o que acontece em função das mudanças observadas no lipopolissacarídeo (LPS) presente na parede celular das bactérias gram-negativas. Essa alteração antigênica é importante para o seguimento da doença e seu diagnóstico sorológico. A fase I possui uma sequência completa de LPS, enquanto que na fase II o microrganismo apresenta modificações do antígeno da parede celular. Tal variação permite distinguir as infecções agudas, onde a produção de anticorpos anti-C. burnetti em fase II é predominante. Quando a doença evolui para a cronicidade, a presença de anticorpos anti- $C$. burnetii fase I é mais acentuada ${ }^{2,21,25}$.

Entre as principais características da C. burnetti está a resistência aos agentes físicos e químicos. No solo, em temperatura ambiente, essa bactéria pode permanecer viável por 4 meses, nas fezes de carrapatos resiste até 36 meses, além disso, é resistente também à radiação ultravioleta. Em relação aos agentes químicos, a bactéria é resistente à solução de hipoclorito de sódio 100mg/ $\mathrm{mL}$ e às variações de $\mathrm{pH}$. Sobrevive por cerca de três dias em formol 0,5\% e 15 minutos em contato com etanol $50 \%{ }^{2}$.

Além da resistência a C. burnetti tem elevado poder infectante, acredita-se que 1 a 10 células microbianas sejam suficientes para desencadear a doença. Por esse motivo, o microrganismo recebeu do Center for Disease Control and Prevention (CDC), classificação que o coloca na categoria B - microrganismos com potencial uso como arma biológica. Nessa categoria estão aqueles considerados fáceis de disseminar e capazes de causar morbidade moderada e mortalidade baixa, sendo o segundo em uma escala de três níveis: A, B e C $2,7,8,10,25,26$.

\section{Transmissão}

Por ser amplamente distribuída na natureza, a bactéria Coxiella burnetii pode ser encontrada em animais domésticos, artrópodes, aves, roedores e marsupiais. No meio rural, os animais infectados, geralmente bovinos e caprinos, funcionam como reservatório da bactéria ${ }^{3,18}$.

A transmissão por meio de vetores, como o carrapato, pode acontecer entre os animais, mas não há evidências da transmissão para humanos $^{21}$. O risco de transmissão para o homem está relacionado à liberação da bactéria no ambiente, por meio da urina, fezes, leite e restos placentários dos reservatórios animais.

Em bovinos e caprinos a doença crônica pode provocar aborto e infertilidade ${ }^{3,18}$. Nas fêmeas infectadas, a bactéria apresenta tropismo pelo útero e glândulas mamárias. Desta forma, o consumo do leite cru e seus derivados, ou mesmo a exposição ocupacional durante a cadeia produtiva (ordenha, beneficiamento e transporte), bem como o contato com os restos placentários dos animais nascidos a termo, ou produtos de aborto, constituem uma forma de transmissão relevan$\mathrm{te}^{2,3,16,18,27}$.

A bactéria liberada no ambiente pode ser livremente dispersa pelo vento e/ou poeira, certas práticas da agricultura, como o hábito de espalhar o estrume pelo campo podem favorecer essa dispersão. Geralmente a infecção acontece mediante inalação de partículas em suspensão no ar ou aerossóis, também pode ocorrer infecção humana pelo contato direto com a fonte do microrganismo $^{3,7,9,10,16,23,27}$.

A transmissão interpessoal é incomum ou pouco relatada, porém, há relatos de transmissão por meio do sêmen ou transfusão de sangue, risco que não pode ser descartado, já que a doença muitas vezes apresenta-se assintomática em sua fase aguda ${ }^{3,8,25}$.

\section{Manifestações clínicas}

\section{Fase aguda}

A Febre Q é geralmente uma doença autolimitada, permanecendo na maioria dos casos assintomática, 40 a $60 \%$ dos pacientes infectados não apresentam sintoma algum ${ }^{28}$. A fase aguda da doença manifesta-se por um acesso febril, calafrios, sudorese, dor de cabeça, fadiga, letargia, 
dor articular e muscular, alterações hematológicas, hepatite aguda e pneumonia atípica, acompanhada de tosse. Estes sintomas são facilmente confundidos com uma gripe ou resfriado, logo, a fase inicial da doença tem seu diagnóstico dificultado $^{2,3,9,18,23,25,29,30}$.

Após a infecção, o período de incubação varia de 10 a 21 dias e os primeiros sintomas podem surgir entre 10 e 90 dias. Períodos de tempo mais longos para a manifestação dos sintomas estão geralmente associados ao contato com baixa carga infectante. Entretanto, condições como idade avançada, gravidez, doenças cardiovasculares ou estado de imunossupressão podem influenciar o curso da infecção. Nas gestantes pode induzir

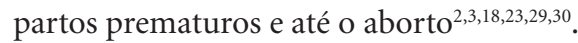

De acordo com Center for Disease Control and Prevention (CDC) cerca de 3\% da população americana saudável e, em torno de 10 a 20\% dos profissionais que se expõem ao risco ocupacional, como veterinários, agricultores e tratadores de animais, apresentam anticorpos para C. burnetii, indicando contato prévio com a bactéria ${ }^{7}$.

\section{Fase crônica}

Após a fase aguda, 1 a 5\% dos casos podem evoluir para a cronicidade. A forma crônica da doença se dá em função de uma resposta imune ineficaz e apresenta evolução lenta, podendo se manifestar meses ou anos após a infecção ${ }^{28}$.

Os grupos mais propensos a evoluir para cronicidade são: mulheres grávidas, pacientes imunodeprimidos ou com algum defeito prévio nas válvulas cardíacas ${ }^{21}$.

Dentre as complicações associadas a essa fase, a endocardite é a manifestação mais comum, apresentando elevada letalidade, principalmente em pacientes com histórico de doença val$\operatorname{var}^{6,18,26,28}$. Siciliano et al. ${ }^{16}$ relatam um caso de endocardite por C. burnetii adquirida em território nacional que levou o paciente a óbito.

Ainda, de acordo com Kampschreur et al. ${ }^{28}$, $40 \%$ dos pacientes portadores de doença valvar pré-existente e que adquirem Febre $\mathrm{Q}$ evoluem para endocardite.

Lamas et al. ${ }^{19}$ investigaram casos de endocardite infeciosa em pacientes de um hospital no Estado do Rio de Janeiro. Durante um período de 12 anos (1998-2009), 64 pacientes com endocardite e cultura de sangue negativa foram submetidos à cirurgia para substituição de válvula, deste total 51 tiveram amostras da vegetação de suas válvulas cardíacas analisadas pela técnica de PCR, para a detecção de C. burnetii, Bartonella spp, Tropheryma whipplei, Staphylococcus aureus,
Streptococcus oralis, Streptococcus bovis, Enterococcus spp, Mycoplasma spp e fungos. Os resultados indicaram 10 casos positivos, sendo S. oralis encontrado em seis amostras isoladamente, Bartonella spp., C. burnetii, S. aureus e a associação S. oralis/Bartonella spp foram identificados em apenas uma amostra.

Entre as manifestações crônicas menos frequentes encontram-se aneurismas da aorta, fibrose pulmonar, infecções ósseas e infecções do fígado ou órgãos reprodutores ${ }^{25}$.

\section{Diagnóstico}

A confluência de sintomas e similaridade com outras afecções expressa a importância do diagnóstico diferencial, entretanto, as dificuldades em realizá-lo corretamente são percebidas tanto na fase aguda quanto na fase crônica da doença $a^{6,29}$.

A pesquisa do agente etiológico da febre $Q$ pode ser feita por diferentes métodos, cuja escolha depende da finalidade da investigação e tipos de amostra pesquisada ${ }^{25,31}$. Os testes disponíveis podem ser classificados em dois tipos: diretos, que visam pesquisar a presença do agente (análise histológica, análise molecular e isolamento) ou indiretos, que detectam por meio de análise sorológica os anticorpos produzidos durante a infecção ${ }^{2}$.

Os métodos sorológicos incluem a Imunofluorescência Indireta (IFI), ELISA e Teste de Fixação do Complemento (CFT). Dentre estes testes, a reação de IFI é o teste padrão em humanos, apesar de suas limitações na fase aguda, em função da demora do corpo em produzir anticorpos. Quando amostras iniciais são coletadas na primeira semana ou assim que os sintomas aparecem, é possível perceber o aumento significativo em até quatro vezes nos títulos de anticorpos, podendo manter-se elevados durante meses. A técnica utiliza antígenos de fase $\mathrm{I}$ e $\mathrm{II}^{2,10,25}$.

Segundo Borriello e Galiero ${ }^{25}$, o teste de ELISA é mais indicado para detecção da doença em animais, apresentando boa especificidade e alta sensibilidade. Já o CFT é o menos utilizado, em função da menor sensibilidade em relação aos demais métodos indiretos. Entretanto, Wegdam -Blans et al..$^{30}$, ao testar a sensibilidade dos métodos sorológicos (IFI, ELISA e CFT) diante de amostras positivas, afirmam que todos apresentam resultado confiável no diagnóstico da febre Q aguda.

A técnica de PCR é um método molecular direto que pode ser utilizado na detecção de frag- 
mentos de DNA em amostras biológicas (sangue e tecido). Pode ser empregada quando se necessita de um diagnóstico precoce da doença. Lemos et al. ${ }^{1}$ publicaram o primeiro estudo que utilizou essa técnica em território nacional, comprovando a ocorrência da Febre Q no país.

Rozental et al. ${ }^{18}$ utilizaram o marcador IS1111 no diagnóstico molecular de um paciente internado, no estado do Rio de Janeiro, apresentando sintomas de febre, mialgia e tosse, inicialmente diagnosticado com pneumonia grave. Foram utilizadas amostras obtidas do lavado broncoalveolar. Foi o primeiro relato de diagnóstico molecular utilizando esse tipo de amostra.

Nos casos de endocardite por C. burnetii, o exame histológico é o mais indicado. Entretanto, não há garantia de um resultado acertado, uma série de interferências como: fibrose, calcificação, vasos deformados e inflamação crônica podem mascarar o resultado, pois estes são aspectos comuns em outras doenças ${ }^{16}$.

$\mathrm{Na}$ pesquisa histológica, a bactéria pode ser identificada e visualizada pelo método de coloração de Gimenez, desenvolvido para identificar Legionella spp. e Rickettsias. O método utiliza corantes biológicos para a detecção de bactérias em amostras de tecido. Apesar de ser um microrganismo gram-negativo, a coloração de gram não é indicada como diagnóstico ${ }^{1,3,21}$.

As técnicas que buscam o isolamento do agente podem ser utilizadas mediante a inoculação da bactéria em ovos de galinha embrionados ou em cultura de células. Tal procedimento é relativamente perigoso do ponto de vista da segurança do manipulador, visto que existe o risco de infecção ${ }^{25}$.

Recentemente, um grupo de pesquisadores descobriu uma forma de cultivo de Coxiella burnetii em meio axênico, o que tem revolucionado as pesquisas sobre a Febre Q e auxiliado a elaboração de vacinas mais seguras ${ }^{32-36}$.

\section{Tratamento}

O tratamento normalmente é indicado nos casos em que a doença atingiu seu estágio crônico e consiste em antibioticoterapia. Nos casos de endocardite recomenda-se intervenção cirúrgica $^{16}$.

A antibioticoterapia indicada na fase aguda emprega doxiciclina, rifampicina, ciprofloxacina, moxifloxacina e claritromicina. O clotrimazol tem sido utilizado em crianças menores de oito anos, o tratamento nessa idade, geralmente, é efi$\mathrm{caz}^{8,18,29}$.
Diante da dificuldade de erradicação da bactéria, o tratamento na fase crônica deve ser prolongado. Doxiciclina associada à hidroxicloroquina ou flouroquinolona são opções de tratamento que devem ser avaliadas com cautela, em função da toxicidade dos fármacos e o tempo necessário, em torno de 18 meses, para erradicação do microrganismo ${ }^{16}$.

Na concepção de Kampschreur et al. ${ }^{28}$, o tratamento combinado de doxiciclina e hidroxicloroquina é o mais indicado para endocardite, havendo apenas uma distinção quanto ao tempo de tratamento. Nos casos onde o paciente não realizou prévia substituição cirúrgica de válvula, o tratamento deve durar por 18 meses e nos casos em que houve intervenção cirúrgica, o tratamento se estende por 24 meses.

Na doença crônica com predomínio de lesão tecidual e títulos elevados de anticorpos IgA e IgG, Irwin et al. ${ }^{29}$ citam o tratamento com doxiciclina, rifampicina e hidroxicloroquina, utilizados em associação, como uma alternativa eficaz.

\section{Prevenção}

Todos os profissionais que lidam diretamente com animais devem utilizar equipamento de proteção individual, especialmente máscara, visto que a inalação de células bacterianas suspensas no ar e aerossóis contaminados são as formas mais comuns de transmissão da doença. Whitney et al. ${ }^{5}$ empregaram as técnicas de ELISA e Imunofluorescência para determinar a sorologia e fatores de risco ocupacional em veterinários nos EUA. Os resultados indicaram que a utilização de máscaras, durante o contato com animais, diminuiu de modo significante a probabilidade de contágio pela bactéria.

Em áreas onde a doença é mais prevalente, medidas de controle devem ser empregadas para conter a transmissão, tais como: controle de carrapatos, higiene constante dos locais de ordenha, adoção de práticas de antissepsia, bem como o uso de equipamentos de proteção individual. Em caso de surto, recomenda-se diminuir a circulação de animais, separando animais doentes de saudáveis e promover o abate de animais doentes. Outras práticas que favorecem o controle do microrganismo envolvem: incineração de materiais de alto risco como os produtos de aborto; tratamento do estrume com cal ou cianeto de cálcio antes do espalhamento sobre o campo; evitar o consumo de leite ou derivados produzidos a partir do leite não pasteurizado 3,37,38.

Uma forma de prevenir a disseminação da zoonose em humanos consiste na vacinação dos 
grupos de risco. Uma vacina obtida a partir da bactéria inativada, disponível desde 1989, é utilizada nas populações de risco na Austrália. De acordo com Irwin et al. ${ }^{29}$, essa vacina é eficaz e confere imunidade celular. No Brasil, essa vacina ainda não está disponível.

As vacinas disponíveis para Febre $Q$ são: Chlamyvax FQ - uma vacina combinada para animais, composta por C. burnetti fase II e Chlamydophyla abortus; Coxevac - obtida a partir de células inteiras da cepa Nine Mile; e Q-Vax para uso humano, obtida a partir de células inteiras de C. burnetii fase I. Todas as vacinas disponíveis são inativadas e apenas uma delas destina-se ao uso em humanos ${ }^{31,39}$.

Para Maurin e Raoult ${ }^{21}$, as vacinas contra Febre Q podem variar de acordo com a fase do agente. Assim, vacinas preparadas com C. burnetii fase I são mais eficientes e oferecem maior proteção do que aquelas preparadas com a fase II do microrganismo.

Em 2000, a Austrália adotou o Programa Nacional de Manejo da Febre Q (NQFMP), implantado aos poucos nas diferentes regiões do país. A vacinação da população só foi iniciada após investigação prévia do histórico de contato com a bactéria, por meio de um teste de sensibilidade à vacina. O objetivo era excluir aqueles indivíduos com imunidade pré-existente para diminuir os riscos de reação adversa à vacina. Primeiramente, foram vacinados trabalhadores dos matadouros e tosqueadores de ovelhas. Na segunda etapa, foram incluídos criadores de ovinos, criadores de gado de corte e de leite, funcionários das fazendas e seus familiares ${ }^{40}$.

Nos anos seguintes, até 2006, quando o programa de financiamento cessou, as taxas de incidência da doença diminuíram. Antes do programa de vacinação, eram notificados entre 600 a 800 casos por ano, após seu início, esse número caiu em aproximadamente $50 \% 0^{27,41}$.

\section{Considerações finais}

O agente etiológico da Febre Q, Coxiella burnetii, é um microrganismo altamente resistente que pode permanecer viável no ambiente por longo período de tempo e provocar uma doença autoli- mitada, com alta infectividade e baixa letalidade. A infecção é essencialmente ocupacional e, na maioria dos casos, afeta pessoas que exercem alguma atividade relacionada à pecuária de corte $\mathrm{e}$ leite. A infecção em humanos geralmente evolui de forma benigna, porém, em alguns casos pode evoluir para a forma crônica da doença, podendo levar o indivíduo a um desfecho fatal.

Destaca-se a importância de um diagnóstico diferencial para a identificação do agente causal. Se a endocardite for provocada pelo agente da $\mathrm{Fe}$ bre $\mathrm{Q}$, a doença requer um tratamento prolongado para sua completa remissão e, se não tratada, pode levar à morte ou aumentar a necessidade de cirurgia. Dessa forma, a realização do diagnóstico microbiológico em pacientes com endocardite faz-se necessária, especialmente em locais onde a Febre Q é mais comum ou em pacientes com histórico de exposição ocupacional.

O Brasil possui o maior rebanho comercial do mundo, é o maior exportador de carne bovina, o segundo maior produtor de carne e o sexto maior produtor de leite ${ }^{42}$. Tais números demonstram a magnitude e importância econômica da atividade pecuária em território brasileiro e alertam para dois pontos críticos. Primeiro, o impacto à produtividade animal, em função da maior frequência de abortos e diminuição da fertilidade do rebanho e, segundo, a grande população de trabalhadores em condição de risco, devido à exposição ocupacional dos profissionais vinculados à pecuária.

O diagnóstico clínico da Febre $\mathrm{Q}$ torna-se relativamente complexo em virtude da sintomatologia inespecífica, gerando dificuldade de reconhecimento ou suspeita da doença pelos profissionais da área da saúde. Nesse contexto, acredita-se que a ocorrência da Febre Q, no Brasil, seja mais comum do que se pensa.

No Brasil não há dados específicos de casos confirmados da zoonose, já que as autoridades sanitárias dispensam sua notificação. Diante da comprovação molecular de casos existentes em nosso país, torna-se necessária a adoção de medidas como: alertar as autoridades sanitárias sobre ferramentas para um diagnóstico rápido e seguro, orientar profissionais que se enquadram nos grupos de risco e elaborar planos para o controle da disseminação da doença. 


\section{Colaboradores}

IAM Damasceno trabalhou na concepção, escrita. RC Guerra trabalhou a concepção, revisão critica e aprovação da versão final do texto apresentado.

\section{Referências}

1. Lemos ERS, Rozental T, Mares-guia MAM, Almeida DNP, Moreira N, Silva RG, Barreira JD, Lamas CC, Favacho AR, Damasco PV. Q Fever as a Cause of Fever of Unknown Origin and Thrombocytosis: First Molecular Evidence of Coxiella burnetii in Brazil. Vector Borne and Zoonotic Dis 2011; 11(1):85-87.

2. Santos AS, Bacellar F, França A. Febre Q: revisão de conceitos. Rev Soc Port de Med Inter 2007; 14(2):90-99.

3. Oyston PCF, Davies C. Q fever: the neglected biothreat agent. J Med Microbiol 2011; 60(1):9-21.

4. Palmela C, Badura R,Valadas E. Acute Q fever in Portugal. Epidemiological and clinical features of 32 hospitalized patients. Germs 2012; 2(2):43-59.

5. Whitney EAS, Massung RF, Candee AJ, Ailes EC, Myers LM, Patterson NE, Berkelman RL. Seroepidemiologic and Occupational Risk Survey for Coxiella burnetii Antibodies among US Veterinarians. Clin Infect Dis 2009; 48(5):550-557.

6. Costa PSG, Brigatte ME, Greco DB. Questing one Brazilian query: reporting 16 cases of $Q$ fever from Minas Gerais, Brazil. Rev Inst Med Tropical 2006; 48(1):5-9.

7. Centers for Disease Control (CDC) Rickettsial Zoonoses Branch. Q Fever, 2011. [acessado 2012 Ago 20]. Disponível em: http://www.cdc.gov/qfever/

8. Delsing CE, Kullberg BJ, Bleeker-Rovers CP. Q fever in the Netherlands from 2007 to 2010. Neth J Med 2010; 68(12):382-387.

9. Dutkiewicz J, Cisak E, Sroka J, Wójcik-Fatla A, Zaj c V. Biological agents as occupational hazards - selected issues. Ann Agric Environ Med 2011; 18(2):286-293

10. Jager MM, Weers-Pothoff G, Hermans MHA, Meekelenkamp JCE, Schellekens JJA, Renders NHM, Leenders ACAP, Schneeberger PM, Wever PC. Evaluation of a Diagnostic Algorithm for Acute Q Fever in an Outbreak Setting. Clin and Vaccine Immunol 2011; 18(6):963-968.

11. Brandão H, Ribeiro do Valle LA, Christovão DA. Investigacão sobre a febre Q em São Paulo. 1. Estudo sorológico em operários de um frigorífico. Arq Fac Hig Saúde Publ Univ São Paulo 1953; 7(1):127-134.

12. Ribeiro-Netto A, Nikitin T, Ribeiro IF. Estudo sobre febre Q em São Paulo: Prevalência em ordenhadores e tratadores de bovinos. Rev Inst Med Trop 1964; 6(6):255-257.

13. Riemann HP, Brant PC, Franti CE, Reis R, Buchanan AM, Stormont C, Behymer DE. Antibodies to Toxoplasma gondii and Coxiella burnetii among students and other personnel in veterinary colleges in California and Brazil. Amer J Epidem 1974; 100(3):197-208.

14. Riemann HP, Brant PC, Behymer DE, Franti CE. Toxoplasma gondii and Coxiella burnetii antibodies among Brazilian slaughterhouse employees. Amer J Epidem 1975; 102(5):386-393.

15. Costa PSG, Brigatte ME, Greco DB. Antibodies to Rickettsia rickettsii, Rickettsia typhi, Coxiella burnetii, Bartonella henselae, Bartonella quintana, and Ehrlichia chaffeensis among healthy population in Minas Gerais, Brazil. Mem Inst Oswaldo Cruz 2005; 100(8):853-859.

16. Siciliano RF, Ribeiro HB, Furtado Remo HM, Castelli JB, Sampaio RO, Santos FCP, Colombo S, Grinberg M, Strabelli TMV. Endocardite por Coxiella burnetii (febre Q). Doença rara ou pouco diagnosticada? Relato de caso. Rev Soc Bras Med Trop 2008; 41(4):409-412. 
17. Lamas CC, Rozental T, Bóia MN, Favacho ARM, Kirsten AH, Silva APM, Lemos ERS. Seroprevalence of Coxiella burnetii antibodies in human immunodeficiency virus-positive patients in Jacarepaguá, Rio de Janeiro, Brazil. Clin Microbiol Infect 2009; 15(Supl. 2):140-141.

18. Rozental T, Mascarenhas LF, Rozenbaum R, Gomes R, Mattos GS, Magno CC, Almeida DN, Rossi MID, Favacho ARM, Lemos ERS. Coxiella burnetii, the agent of Q fever in Brazil: its hidden role in seronegative arthritis and the importance of molecular diagnosis based on the repetitive element IS1111 associated with the transposase gene. Mem Inst Oswaldo Cruz 2012; 107(5):695697.

19. Lamas CC, Ramos RG, Lopes GQ, Santos MS, Golebiovski WF, Weksler C, Ferraiuoli GID, Fournier PE, Lepidi H, Raoult D. Bartonella and Coxiella infective endocarditis in Brazil: molecular evidence from excised valves from a cardiac surgery referral center in Rio de Janeiro, Brazil, 1998 to 2009. Int J Infec Dis 2013; 17(1):65-66

20. Mares-guia MAMM, Rozental T, Guterres A, Gomes R, Almeida DN, Moreira NS, Barreira JD, Favacho AR, Santana AL, Lemos ERS. Molecular identification of the agent of Q fever - Coxiella burnetii - in domestic animals in State of Rio de Janeiro, Brazil. Rev Soc Bras Med Trop 2014; 47(2):231-234.

21. Maurin M, Raoult D. Q Fever. Clin Microbiol Rev 1999; 12(4):518-553.

22. Leite ZTC, Vaitsman DS, Dutra PB, Guedes A. Leite e alguns de seus derivados: da antiguidade à atualidade. Quim Nova 2006; 29(4):876-880.

23. Shannon J, Heinzen RA. Adaptive Immunity to the Obligate Intracellular Pathogen Coxiella burnetii. National Institutes of Health 2009; 43(1-3):138-148.

24. Voth DE, Heinzen RA. Lounging in a lysosome: the intracellular lifestyle of Coxiella burnetii. Cell Microbiol 2007; 9(4):829-840.

25. Borriello G, Galiero G. Coxiella burnetii. In: Lorenzo-Morales J, organizador. Zoonosis. Zagrebe: InTech; 2012. Cap. 5, p. 65-88.

26. Hartzell JD, Peng SW, Wood-Morris R, Sarmiento DM, Collen JF, Robben PM, Moran KA. Atypical Q Fever in US Soldiers. Emerg Infect Dis 2007; 13(8):1247-1249.

27. Chiu CK, Durrheim DNA. Review of the efficacy of human $\mathrm{Q}$ fever vaccine registered in Australia. N.S.W. Public Health Bull 2007; 18(7-8):133-136.

28. Kampschreur LM, Oosterheert JJ, Vries feyens CA, Delsing CE, Hermans M HA, Van Sluisveld ILL, Lestrade PJ, Renders NHM, Elsman P, Wever PC. Chronic Q Fever-Related Dual-Pathogen Endocarditis: Case Series of Three Patients. J Clin Microbiol 2011; 49(4):16921694.

29. Irwin MJ, Lloyd AR, Massey PD. Bug Breakfast in the Bulletin: Q fever. NSW Public Health Bulletin 2007; 18(7-8):137-138.

30. Wegdam-Blans MCA, Wielders CCH, Meekelenkamp J, Korbeeck JM, Herremans T, Tjhie HT, Bijlmer HA, Koopmans MPG, Schneeberger PM. Evaluation of Commonly Used Serological Tests for Detection of Coxiella burnetii Antibodies in Well-Defined Acute and Follow-Up Sera. Clin Vaccine Immunol 2012; 19(7):1110-1115
31. Angelakis E, Raoult DQ. Fever. Vet Microbiol 2010; 140(3-4):297-309.

32. Omsland A, Cockrell DC, Fischer ER, Heinzen RA. Sustained axenic metabolic activity by the obligate intracelular bacterium Coxiella burnetii. J Bacteriol 2008; 190(9):3203-3212.

33. Omsland A, Cockrell DC, Howe D, Fischer ER, Virtaneva K, Stur- Devant DE, Porcella SF, Heinzen RA. Host cell-free growth of the Coxiella burnetii. Proc Natl Acad Scin USA 2009; 106(11):4430-4434.

34. Omsland A, Beare PA, Hill J, Cockrell DC, Howe D, Hansen B, Samuel JE, Heinzen RA. Isolation from animal tissue and genetic transformation of Coxiella burnetii are facilitated by anim proved axenic growth medium. Appl Environ Microbiol 2011; 77(11)3720-3725.

35. Ruiz S, Wolfe DN. Vaccination against $Q$ fever for biodefense and public health indications. Front Microbiol 2014; 5(16):1-7.

36. Van Schaik EJ, Chen C, Mertens K, Weber MM, Samuel JE. Molecular pathogenesis of the obligate intracellular bacterium Coxiella burnetii. Nat Ver Microbiol 2013; 11(8):561-573.

37. Roca B. Fiebre Q. An Med Interna, 2007; 24(11):558560 .

38. Schimmer B, Lenferink A, Schneeberger P, Aangenend H, Vellema P, Hautvast J, Van Duynhoven Y. Seroprevalence and Risk Factors for Coxiella burnetii (Q Fever) Seropositivity in Dairy Goat Farmers' Households in The Netherlands, 2009-2010. PLoS One 2012; 7(7):110

39. United States Department of Agriculture (USDA). Evaluation of factors that would initiate or propagate epidemic coxiellosis in the U.S. domesticated goat population. Washington: Centers for Epidemiology and Animal Health; 2013

40. Gidding HF, Wallace C, Lawrence GL, Mcintyre PB. Australia's national Q fever vaccination program. Vaccine 2009, 27(14):2037-2041.

41. Hendry S. Q fever - cut the bull! Med Stud J Australia 2012; 4(1):43-46

42. Brasil. Ministério da Agricultura Pecuária e Abastecimento (MAPA). Plano mais pecuária/Ministério da Agricultura, Pecuária e Abastecimento. Brasília: MAPA; 2014.

Artigo apresentado em 06/10/2016

Aprovado em 26/01/2017

Versão final apresentada em 28/01/2017 
